\title{
Enfermedad gonocócica diseminada. Reporte de un caso clínico
}

\author{
Disseminated gonococcal disease. Report of a clinical case \\ Doença gonocócica disseminada. Relato de um caso clínico
}

Cynthia Ferreira ORCID: 0000-0001-8027-0366 Médico. Ex Residente Medicina Interna. Hospital Pasteur. UdelaR.

Mercedes Perendones ORCID: 0000-0002-3846-2396 Internista. Hepatóloga. Profesor Agregado Clínica Médica. UdelaR.

Resumen: La infección gonocócica, es una infección de transmisión sexual en aumento en las últimas décadas. La propagación de Neisseria gonorrhoeae al torrente sanguíneo ocasiona una enfermedad diseminada, siendo las principales manifestaciones clínicas las articulares y cutáneas. Se presenta el caso clínico de una mujer joven que se presenta con la tríada típica. Se revisan los criterios diagnósticos y terapéuticos.

Palabras claves: enfermedad gonocócica diseminada.

Abstract: Gonococcal infection is a sexually transmitted infection on the rise in recent decades. The spread of Neisseria gonorrhoeae to the bloodstream causes a disseminated disease, the main clinical manifestations being joint and cutaneous. The clinical case of a young woman presenting with the typical triad is presented. Diagnostic and therapeutic criteria are reviewed.

Key words: disseminated gonococcal disease.

Resumo: A infecção gonocócica é uma infecção sexualmente transmissível que vem crescendo nas últimas décadas. A propagação de Neisseria gonorrhoeae para a corrente sanguínea causa uma doença disseminada, sendo as principais manifestações clínicas articulares e cutâneas. É apresentado o caso clínico de uma jovem apresentando a tríade típica. Os critérios diagnósticos e terapêuticos são revisados.

Palavras-chave: doença gonocócica disseminada.

Recibido: 22/06/2020 Aceptado: 07/10/2020

Clínica Médica 2. Prof. Dra. Mabel Goñi. Hospital Pasteur. Facultad de Medicina. Universidad de la República (UdelaR). Montevideo, Uruguay.

Correspondencia: E-mail: draperendones@adinet.com.uy 


\section{Introducción}

La infección gonocócica es un problema de salud pública a nivel mundial, siendo la segunda infección de transmisión sexual bacteriana más prevalente.

El agente etiológico es Neisseria gonorrhoeae, un diplococo gramnegativo, principal responsable de uretritis en hombres; en las mujeres hasta un $50 \%$ de las infecciones pueden ser asintomáticas.

La enfermedad gonocócica diseminada (EGD) se produce por la propagación de Neisseria gonorrhoeae al torrente sanguíneo. Las principales manifestaciones clínicas son las articulares, pueden aparecer en forma de la tríada típica de poliartralgias, rash y tenosinovitis o como una artritis purulenta sin otras lesiones ${ }^{(1,2)}$

Se presenta el caso clínico de una mujer joven que se presenta con la tríada típica, se revisan los criterios diagnósticos y terapéuticos.

\section{Caso clínico}

Paciente sexo femenino, de 19 años, procedente de Montevideo, empleada de un supermercado. Como antecedentes personales presenta factores de riesgo para enfermedades de transmisión sexual.

Consultó en emergencia por dolor en articulaciones metacarpo-falángicas proximales bilaterales, rodilla derecha, metatarsianas a derecha de dos semanas de evolución. Se acompañaba de tumefacción, calor local y rubor. Calmaba parcialmente con anti-inflamatorios no esteroideos. Concomitantemente presentaba lesiones en miembros superiores e inferiores de tipo maculo de pequeño tamaño, no forman vesículas, no eran pruriginosas ni dolorosas.

Al examen físico se constató paciente lúcida, febril $\left(37.8^{\circ} \mathrm{C}\right.$ axilar). Piel y mucosas normocoloreadas. Presentaba lesiones eritematosas tipo maculo pápulas de $0.4 \mathrm{~mm}$, no confluentes en miembros inferiores, palmas y plantas de pies. No presentaba lesiones a nivel bucofaríngeo. A nivel de cuello, axila e ingle no se objetivaron adenomegalias. Al examen cardiovascular tenía un ritmo regular de $110 \mathrm{cpm}$, con ruidos normofonéticos y silencios libres. Presión arterial 110/80 mmHg. Al examen osteoarticular destacabamos la presencia de tumefacción con calor y rubor a nivel de la rodilla derecha y ambos tobillos. Dolor a la palpación de la interlínea articular de rodilla derecha con limitación a la movilización. Dolía a la palpación de articulación tibio-tarsiana derecha, con limitación a la movilización. En el examen genital no se objetivaban lesiones ni corrimiento. El resto del examen físico no presentaba alteraciones a destacar.

Con planteo de poliartritis de pequeñas y medianas articulaciones, junto a la presencia de lesiones cutáneas, de etiología infecciosa, subaguda, se realiza ronda bacteriológica que incluyó:

Hemocultivo de sangre periférica (dos determinaciones): Neisseria gonorrhoeae, sensible a Ceftriaxona.

Urocultivo: sin desarrollo bacteriano

Exudado vaginal y faríngeo: sin desarrollo bacteriano

A los efectos de valorar otras localizaciones del agente infeccioso, se realiza Ecocardiograma transtorácico y transesofágico que no evidenció lesiones compatibles con endocarditis infecciosa y Tomografía axial computarizado de tórax/abdomen/pelvis que fue normal.

De la analítica sanguínea se destacaba: leucocitosis $18.420 / \mathrm{mm} 3$, neutrófilos $88 \%$, linfocitos $5,4 \%$, hemoglobina $12.8 \mathrm{~g} / \mathrm{dL}$, hematocrito $42 \%$, plaquetas $242.000 \mathrm{~mm} 3$. Proteína C reactiva $160 \mathrm{mg} / \mathrm{L}$.

Azoemia, creatininemia, ionograma, hepatograma y crasis eran normales.

Las serologías para virus de inmunodeficiencia humana, hepatitis B y C fueron negativas. La prueba antitreponémica también fue negativa.

Se comenzó tratamiento con Ceftriaxona 2 gr intravenosos/día asociado a Azitromicina 1 gr vía oral en dosis única. Se realiza denuncia a la división epidemiología del Ministerio Salud Pública. 
A los tres días se constató aumento de los signos inflamatorios del tobillo derecho. Se realiza centellograma óseo que evidenció lesiones óseas activas hiperémicas en tarso derecho, primer y segundo cuneiforme, compatibles con planteo de osteomielitis (figura 1).

Figura 1: Centellograma óseo. Se observa hipercaptación a nivel del tarso
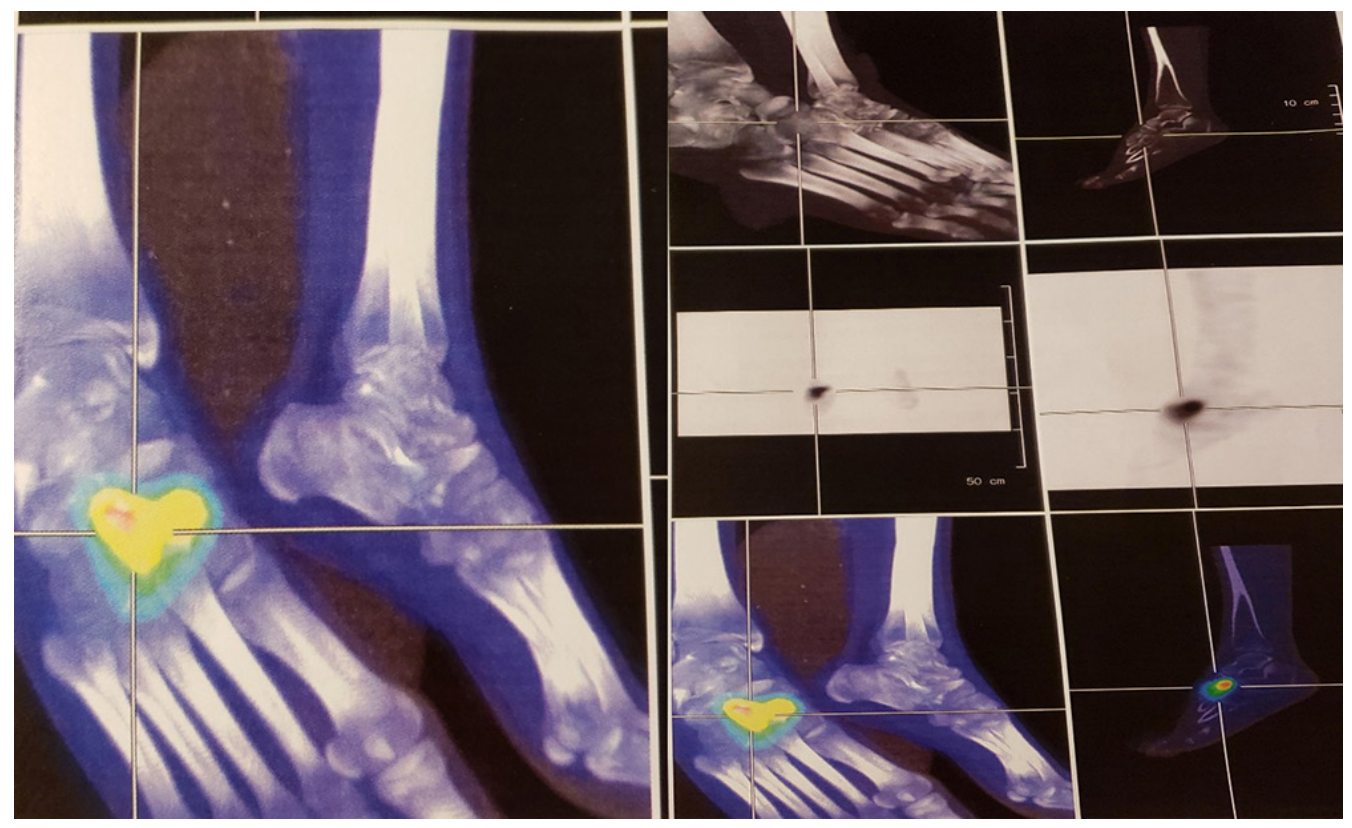

Los hemocultivos de control a los 10 días del tratamiento antibióticos fueron negativos. Se otorgó alta hospitalaria al cumplir los 14 días del plan antibiótico propuesto, estando la paciente asintomática.

\section{Discusión}

Neisseria gonorrhoeae fue una causa frecuente de artritis infecciosa en la década de los 70 y 80 , posteriormente los casos descienden hasta en un $70 \%$, teniendo en la última década un incremento de su incidencia ${ }^{(3)}$.

Suele presentarse como una enfermedad localizada que compromete el tracto genitourinario (uretritis, orquitis, epididimitis, vesiculitis seminal y prostatitis en el hombre; y endometritis, salpingitis, ovaritis y en fermedad pelviana inflamatoria, con aumento de riesgo de embarazo ectópico y esterilidad en la mujer), el tracto gastrointestinal (faringitis, proctitis) o el peritoneo (perihepatitis). Con menor frecuencia lo hace como una infección diseminada.

La enfermedad gonocócica diseminada (EGD) se produce por la propagación de Neisseria gonorrhoeae al torrente sanguíneo ${ }^{(1)}$ y ocurre aproximadamente en el 0.5 al $3 \%$ de las infecciones gonocócicas ${ }^{(4)}$.

La EGD es también conocida como síndrome artritis-dermatitis debido a sus dos manifestaciones más frecuentes. Menos frecuente es la tríada típica de poliartralgias, rash y tenosinovitis.

También se puede presentar como una artritis purulenta habitualmente monoarticular, sin otras lesiones. Ambas presentaciones pueden superponerse o evolucionar de una a otra ${ }^{(2)}$.

Es más frecuente en mujeres y se relaciona con la menstruación, final del embarazo, uso de dispositivos intrauterinos ${ }^{(4)}$. Son también factores predisponentes el lupus eritematoso sistémico, la infección por virus inmunodeficiencia humana $(\mathrm{VIH})$ y el déficit del complemento sérico (congénito o adquirido) ${ }^{(1,2,5-12)}$.

El cuadro se desarrolla luego de 2 a 3 semanas de la infección primaria o a la semana de la última menstruación ${ }^{(7,8)}$.

Las lesiones cutáneas se han reportado hasta en el 60 - 75\% de los casos. Las más comunes suelen ser máculas, pápulas o pústulas hemorrágicas que pueden desarrollar un centro necrótico, asientan sobre una base eritematosa. Menos frecuentes son las ampollas hemorrágicas, las petequias, lesiones similares a eritema nodoso, eritema multiforme y urticaria ${ }^{(1,5,7,10)}$. 
Aparecen precozmente, son indoloras y se localizan en las zonas distales de las extremidades y en el tronco $\left.{ }^{(2,3,13}\right)$, se consideran debidas a vasculitis por embolia séptica ${ }^{(4,6-8)}$.

La afectación articular se inicia con una tenosinovitis que cursa con dolor, tumefacción y eritema periarticular. Se observa en el $50-68 \%$ de los casos yes asimétrica. Ocurre principalmente en muñecas, tobillos y dedos de las manos o los pies ${ }^{(1,4,10,13)}$.

La presencia de tenosinovitis de varios tendones que compromete muñecas, dedos y tobillos en un paciente en etapa sexual activa debe hacer sospechar este diagnóstico (13).

La artritis, se observa entre 40 - $85 \%$ de los casos, generalmente es monoarticular y predomina en orden decreciente en las rodillas, muñecas, tobillos, codos y las articulaciones metacarpofalángicas ${ }^{(2-4,13)}$.

En ausencia de la dermatitis característica o de una infección genital manifiesta, la artritis gonocócica es indistinguible clínicamente de otras formas de artritis séptica ${ }^{(3)}$.

La patogénesis de la artritis aún no está clara. Se ha encontrado que los microorganismos llegan a la cavidad articular a través de la diseminación hematógena, favorecida por la rica vascularidad sinovial y la ausencia de membrana basal, induciendo rápidamente una sinovitis inflamatoria aguda. Adicionalmente, las características del germen (presencia de apéndices filamentosos, proteínas de membrana que inactivan el complemento e inhiben la fusión de los fagolisosomas dentro de los neutrófilos) favorecen el daño articular ${ }^{(13)}$.

En la actualidad la afectación cardíaca (endocarditis, miocarditis o pericarditis), hepática y meníngea son complicaciones infrecuentes ${ }^{(1,4,6,6)}$.

El diagnóstico se base en la clínica, epidemiología compatible y el aislamiento de $\mathrm{N}$. gonorrhoeae de líquido articular y/o hemocultivos ${ }^{(2)}$.

Las principales herramientas diagnósticas son ${ }^{(4)}$ :

a) Examen microscópico, mediante tinción de Gram o azúl de metileno. Es útil en el diagnóstico rápido de uretritis gonocócica con una sensibilidad y especificidad del $95 \%$. Sin embargo la misma es baja en varones asintomáticos, exudados endocervicales, exudados rectales y faríngeos, por lo que no es una herramienta útil para descartar estas infecciones.

b) Cultivo. Permite hacer el diagnóstico definitivo mediante el aislamiento y la identificación del microorganismo. Es de alta sensibilidad y especificidad, además de ser la única que permite monitorizar las resistencias antimicrobianas. Es adecuado para muestras endocervicales, uretrales, orina, rectales, faríngeas y conjuntivales con un rendimiento del 25 al 100\%. El $80 \%$ de los pacientes con artritis gonocócica tienen un cultivo positivo de la muestra de las mucosas (uretra, recto, faringe, endocérvix y conjuntiva), revelándose como la mejor opción para el aislamiento del gonococo (3). Los hemocultivos deben realizarse con una concentración de polianetol sulfonato de sodio menor al $0.025 \%$ ya que el gonococo es sensible a este compuesto y se inactiva. Suelen ser positivos al comienzo del cuadro, pero luego su sensibilidad disminuye al $50 \%$. Los cultivos de líquido sinovial son sólo positivos en la fase de artritis, aumenta la sensibilidad que el cultivo se realice de líquido sinovial centrifugado durante 15 minutos ${ }^{(3,12)}$. Los cultivos de las lesiones cutáneas son habitualmente negativos ${ }^{(7,12,14,15)}$.

c) Técnicas de amplificación de ácido nucleicos (TAAN). Detectan microorganismos no viables, aumentando la sensibilidad. Actualmente se disponen de medios comerciales basados en la amplificación de ácidos nucleicos por PCR a tiempo real, para el diagnóstico de infección por N. gonorrhoeae. Estas estrategias ofrecen mayor sensibilidad que el cultivo, aunque también pueden dar falsos positivos debido a reacciones cruzadas con N. meningitidis ${ }^{(3)}$.

Desde que a principios del siglo XX se introdujo el uso de antibióticos en el tratamiento de la gonorrea, se ha incrementado la resistencia de N. gonorrhoeae a todos los antibióticos utilizados a lo largo de la historia.

Desde 2011 todas las guías recomiendan una pauta dual con ceftriaxona y azitromicina como terapia inicial (4), pero en los últimos años la resistencia a esta última también está aumentando, con lo que el tratamiento dual se está poniendo en duda por parte de las sociedades científicas. 
En 2016, el programa European Gonococcal Antimicrobian Surveillance Programme (Euro GASP) estudió 2.660 cepas de gonococo aisladas en 25 países participantes. Se detectaron $2.1 \%$ de resistencia a cefixima, $7.5 \%$ a azitromicina y $46.5 \%$ a ciprofloxacina. No se detectaron resistencia a la ceftriaxona ${ }^{(4)}$.

En la tabla 1 se presentan las recomendaciones de tratamiento en infección gonocócica disemina (4).

\begin{tabular}{|c|c|}
\hline $\begin{array}{l}\text { IUSTI Europe, EADV, EDF, UEMS, } \\
\text { ECDC y WHO-Europe. } 2012\end{array}$ & BASHH. 2011 \\
\hline Ceftriaxona im 0 iv $1 \mathrm{~g} / 24 \mathrm{hs} 7$ días & Ceftriaxona im o iv $1 \mathrm{~g} / 24 \mathrm{hs} 7$ días \\
\hline 0 & 0 \\
\hline Espectinomicina im $2 \mathrm{~g} / 12 \mathrm{hs} 7$ días & Cefotaxima iv $1 \mathrm{~g} / 8 \mathrm{hs}$ \\
\hline Pasar a vo tras 1-2 días de & 0 \\
\hline $\begin{array}{l}\text { mejoría: cefixima } 400 \mathrm{mg} / 12 \mathrm{hs} \text {, } \\
\text { si es sensible ciprofloxacina } \\
500 \mathrm{mg} / 12 \mathrm{hs}\end{array}$ & $\begin{array}{l}\text { Si es sensible Ciprofloxacina iv } \\
500 \mathrm{mg} / 12 \mathrm{hs} \text { o espectinomicina im } \\
2 \mathrm{~g} / 12 \mathrm{hs} 7 \text { días }\end{array}$ \\
\hline Hasta 7 días de tratamiento total & $\begin{array}{l}\text { Pasar a vo tras } 1-2 \text { días de mejoría: } \\
\text { cefixima } 400 \mathrm{mg} / 12 \mathrm{hs} \text { o si es sensible } \\
\text { ciprofloxacina } 500 \mathrm{mg} / 12 \mathrm{hs} \text { hasta } 7 \text { días } \\
\text { de tratamiento total }\end{array}$ \\
\hline
\end{tabular}

\section{CDC. 2015}

Artritis y síndrome artritis-dermatitis: Ceftriaxona im 0 iv $1 \mathrm{~g} / 24 \mathrm{hs} 7$ días + azitromicina $1 \mathrm{~g}$ vo monodosis

Pasar a vo tras 1-2 días de mejoría hasta un total de 7 días.

Meningitis: Ceftriaxona iv $1-2 \mathrm{~g} / 12$ $24 \mathrm{hs} 10$ a 14 días + azitromicina $1 \mathrm{~g}$ vo monodosis

Endocarditis: Ceftriaxona iv $1-2 \mathrm{~g} / 12-$

24hs 4 semanas + azitromicina $1 \mathrm{~g}$ vo monodosis

AEDV: Academia Española de Dermatología y Venereología. BASSH: Bristish Association for Sexual Health and HIV. CDC: Centers for Disease Control and Prevention. ECDC: European Centre for Disease Prevention and Control. EDF: European Dermatology Forum. IUSTI: International Union against Sexually Transmitted Infection. UEMS: Union Européenne des Médecins Spécialistes. WHO: World Health Organization. im- intramuscular iv - intravenoso vo-vía oral

Por último, se debe destacar la importancia de la búsqueda y tratamiento de los contactos sexuales, lo cual no fue posible efectuar en el caso presentado ${ }^{(16)}$.

\section{Conclusiones}

Estamos ante una entidad clínica que ha aumentado su frecuencia, debiendo el equipo de salud tenerla presente cuando se presentan pacientes en etapa sexual activa y con la sintomatología referida.

\section{Bibliografía}

1- Ram S, Rice P. Infecciones gonocócicas. En: Jameson JL ed. Harrison Principios de medicina interna. México: Ed. McGraw Hill; 2009. pp 914-920.

2- Benavent Nuñez D, Tornero Marína C, Bonilla Hernán G, García Perea A, Balsa Criado A, Rico Nieto A. Artritis gonocócica y déficit de C2. Reumatol Clin 2019; 15(6): e125-e127. doi:10.1016/j. reuma.2017.08.010

3- Aguadero V, Baena I, Fernández C, Sánchez J, Sánchez JL. Diagnóstico clínico y de laboratorio de la artritis gonocócica: a propósito de un caso. Rev Lab Clin. 2013; 6(1):37-40

4- Barberá MJ, Serra-Pladevall J. Infección gonocócica: un problema aún sin resolver. Enferm Infecc Microbiol Clin. 2019; 37(7):458-466 doi: 10.1016/j.eimc.2018.12.008

5- García A, Madkan V, Tyring S. Gonorrea y otras enfermedades venéreas. En: Fitzpatrick TB, Freedberg IM, Eisen AZ, Wolff K, et al. Dermatología en Medicina General. Buenos Aires: Panamericana; 2009. pp. 1993-1996.

6- Stary A. Enfermedades de transmisión sexual. En: Bolognia J, Jorizzo J, Rapini R. Dermatología. Madrid: Elsevier; 2004, 1282-1287.

7- Brown T, Yen-Moore A, Tyring S. An overview of sexually transmitted diseases, part. I. J. Am. Acad. Dermatol. 1999; 41: 511-529.

8- Mehrany K, Kist J, O’ Connor W, DiCaudo D. Disseminated gonococcemia. Int. J. Dermato. 2003; 42: 208-209.

9- Marini M, Oxilia M. Las enfermedades de transmisión sexual en los tiempos del sida. Supuraciones urogenitales. Buenos Aires: Marymar; 1999. pp 85-110. 
10- Rice P. Gonococcal arthritis (disseminated gonococcal infection). Infect Dis Clin North Am. 2005; 19: 853-861.

11- Raychaudhuri M, Peall A, Page C, Browning M. A case of duplicitous diplococci. Sex Transm Infect. 2009; 85: 441-442.

12- Suzaki A, Hayashi K, Kosuge K, Soma M, Hayakawa S. Disseminated gonococcal infection in Japan: a case report and literature review. Intern Med. 2011; 50(18):2039-43.

13- Ochoa Rojas C, Izquierdo J. Papel de la ecografía articular en el diagnóstico diferencial de la poliartritis aguda. Aspectos ecográficos de la artritis gonocócica: a propósito de un caso. Rev Colomb Reumatol. 2013; 20(2):116-120

14- Kimmitt P, Kirby A, Perera M, Nicholson K, et al. Identification of Neisseria gonorrhoeae as the causative agent in a case of culture negative dermatitis arthritis syndrome using real time PCR. J Travel Med. 2008; 15: 369-371.

15- Read P, Abbott R, Pantelidis P, Peters BS, White JA. Disseminated gonococcal infection in a homosexual man diagnosed by nucleic acid amplification testing from a skin lesion swab. Sex Transm Infect. 2008 Oct; 84(5):348-9.

16- Sociedad Argentina de Dermatología. Infecciones de transmisión sexual. Pautas de tratamiento Actualización [en línea]. Buenos Aires: SAD; 2008 [citado 07/09/2020]. Disponible en: www.sad.org.ar/ file_download/13/transex.pdf

\section{Aporte cada autor al trabajo}

Cynthia Ferreira: Concepción y diseño del trabajo. Recolección de datos. Redacción del manuscrito.

Mercedes Perendones: Redacción del manuscrito. Revisión crítica del manuscrito. 